\title{
Nicotine Dependency and Readiness to Quit Smoking among Patients with Hidradenitis Suppurativa
}

\author{
Allard R.J.V. Vossen Kelsey R. van Straalen Evi F.H. Swolfs \\ Jonathan F. van den Bosch Christine B. Ardon Hessel H. van der Zee \\ Department of Dermatology, Erasmus University Medical Center, Rotterdam, The Netherlands
}

\section{Dear Editor,}

Smoking is a well-established risk factor for hidradenitis suppurativa (HS). Up to $90 \%$ of patients with HS are active or former smokers [1]. The pathogenic role of smoking in HS is highlighted by the better long-term prognosis seen in patients who quit smoking [2]. Therefore, smoking cessation could be a crucial part of the management of HS. We aimed to assess whether nicotine dependency, a patient's confidence in their ability to refrain from smoking, and readiness to quit differed between HS patients and controls.

A cross-sectional study was performed among consecutive, active-smoking patients with HS visiting the specialised HS outpatient clinic of the Erasmus University Medical Center and its affiliated outpatient clinic DermaHaven in Rotterdam, The Netherlands, between August 2018 and April 2019. Randomly selected, currently smoking, non-HS patients attending the Department of Dermatology were included as controls. All patients filled out a questionnaire on their smoking habits and 3 additional, validated smoking-related questionnaires: the Fägerstrom Test for Nicotine Dependence (FTND), which assesses the degree of dependency [3]; the Smoking SelfEfficacy Questionnaire 12 (SEQ-12), which assesses a pa- tient's confidence in their ability to refrain from smoking [4], and Readiness to Quit Smoking (RtQ) in the past 12 months and within the next 6 months. Patient characteristics were collected through the HiScreen Registry (MEC-2016-426) and/or patient charts. Differences between HS patients and controls were assessed using Student $t$ tests, Mann-Whitney $U$ tests, or $\chi^{2}$ tests where appropriate. The study was approved by the local Institutional Review Board (MEC-2018-1127). All patients gave their consent for study participation.

In total $108 \mathrm{HS}$ patients and 111 controls were included (Table 1). Most of the control patients attended the clinic for eczema (23\%; the vast majority atopic dermatitis), psoriasis (16\%), or a cutaneous malignancy (12\%). The included controls were significantly older compared with the HS patients (mean age $45 \pm 14$ vs. $41 \pm 13$ years, respectively, $p=0.01$ ). Patients with HS did not show a significantly different degree of smoking dependency, measured with the FTND, compared with controls.

A.R.J.V.V. and K.R.v.S. contributed equally to this work. The Department of Dermatology, Erasmus University Medical Center, is an ERN-Skin member.

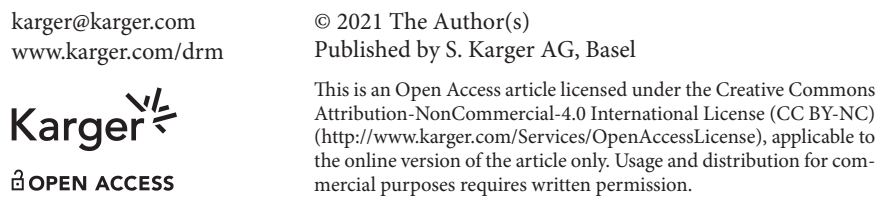

karger@karger.com www.karger.com/drm

(C) 2021 The Author(s)

Published by S. Karger AG, Basel

This is an Open Access article licensed under the Creative Commons Attribution-NonCommercial-4.0 International License (CC BY-NC) (http://www.karger.com/Services/OpenAccessLicense), applicable to the online version of the article only. Usage and distribution for commercial purposes requires written permission.

Allard. R.J.V. Vossen

Erasmus University Medical Center

Dr. Molewaterplein 40

NL-3015 GD Rotterdam (The Netherlands)

a.vossen@erasmusmc.nl 
Table 1. Characteristics and smoking habits of patients with HS and controls

\begin{tabular}{|c|c|c|c|}
\hline & HS $(n=108)$ & $\begin{array}{l}\text { Controls } \\
(n=111)\end{array}$ & $p$ value \\
\hline Female sex & $72(66.7)$ & $61(55.0)$ & 0.10 \\
\hline Age, years & $41 \pm 13$ & $45 \pm 14$ & 0.01 \\
\hline $\mathrm{BMI}$ & $27.65 \pm 5.64$ & & \\
\hline Normal weight & $35(35.7)$ & & \\
\hline Overweight & $33(33.7)$ & & \\
\hline Obese & $30(30.6)$ & & \\
\hline Missing & 10 & & \\
\hline Age at onset of HS, years & $20(14-30)$ & & \\
\hline Missing & 8 & & \\
\hline \multicolumn{4}{|l|}{ Hurley stage } \\
\hline Hurley stage I & $65(60.2)$ & & \\
\hline Hurley stage II & $40(37.0)$ & & \\
\hline Hurley stage III & $3(2.8)$ & & \\
\hline Age when started smoking, years & $16(14-17)$ & $16(14-18)$ & 0.32 \\
\hline Missing & 0 & 2 & \\
\hline Total cigarettes a day & $14(8-20)$ & $10(7-15)$ & 0.06 \\
\hline FTND score & $3.0(2.0-5.0)$ & $3.0(1.0-5.0)$ & 0.07 \\
\hline Missing & 1 & 1 & \\
\hline SEQ-12 score & $30.0(24.0-40.0)$ & $29.5(22.0-40.0)$ & 0.34 \\
\hline Missing & 11 & 17 & \\
\hline Intrinsic stimuli & $16.7 \pm 6.8$ & $15.4 \pm 6.2$ & 0.17 \\
\hline Missing & 3 & 5 & \\
\hline Extrinsic stimuli & $15(11-22)$ & $14(9-21)$ & 0.07 \\
\hline Missing & 7 & 16 & \\
\hline \multicolumn{4}{|l|}{ RtQ past 12 months } \\
\hline Yes & $51(47.2)$ & $42(37.8)$ & 0.17 \\
\hline \multicolumn{4}{|l|}{ RtQ next 6 months } \\
\hline Yes & $62(59.6)$ & $55(51.4)$ & 0.23 \\
\hline Missing & 4 & 4 & \\
\hline
\end{tabular}

Data are presented as $n, n(\%)$, the mean $\pm \mathrm{SD}$, or median (IQR). BMI was only collected for patients with HS. HS, hidradenitis suppurativa; FTND, Fägerstrom Test for Nicotine Dependence; SEQ-12, Self-Efficacy Questionnaire 12; RtQ, Readiness to Quit Smoking.

There was no significant difference between the proportion of HS patients and controls who had attempted to quit smoking in the past 12 months ( 47.2 vs. $37.8 \%, p=$ 0.17 ), or who were considering quitting smoking in the upcoming 6 months (59.6 vs. $51.4 \%, p=0.23)$. Nicotine dependency including the effect of intrinsic or extrinsic stimuli, or readiness to quit smoking among HS patients were not significantly associated with either age, body mass index, disease duration, or disease severity (Hurley stage).

In summary, this study shows that smoking HS patients experience the same level of nicotine dependency, and comparable readiness to quit as controls. The major strengths of this study are the use of validated questionnaires and a control group. The main limitation is that the groups are relatively small and not matched, for example, for age. However, we do not expect the difference in age between the groups to have influenced the results as a previous study among 1,378 Dutch smokers demonstrated that there was no correlation between age and FTND score [5].

Smoking cessation improves the long-term prognosis of HS as well as general health. Therefore, motivating patients for and supporting them through the process of smoking cessation is an integral part of the treatment of HS. Guidance in smoking cessation is tapered to a patient's individual level of dependency, their readiness to quit, and their confidence in their ability to refrain from smoking. This study suggests that smoking cessation among HS patients can be attempted through regular in- 
terventions without the need for different strategies, as nicotine dependency and factors influencing self-efficacy and readiness to quit do not differ between HS patients and controls.

\section{Key Message}

Nicotine dependency and readiness to quit smoking are similar between hidradenitis suppurativa patients and controls.

\section{Statements of Ethics}

The study was approved by the Institutional Review Board of the Erasmus University Medical Center.

\section{Conflict of Interest Statement}

The authors have no conflicts of interest to declare.

\section{Funding Sources}

There are no funding sources to declare.

\section{Author Contributions}

A.R.J.V.V.: conceptualization, methodology, validation, review and editing. K.R.v.S.: methodology, formal analysis, writing original draft, review and editing. E.F.H.S. and J.F.v.d.B.: data curation, review and editing. C.B.A. and H.H.v.d.Z.: supervision, review and editing.

\section{References}

1 Vossen AR, van der Zee HH, Prens EP. Hidradenitis suppurativa: a systematic review integrating inflammatory pathways into a cohesive pathogenic model. Front Immunol. 2018 Dec;9:2965.

2 Kromann CB, Deckers IE, Esmann S, Boer J, Prens EP, Jemec GB. Risk factors, clinical course and long-term prognosis in hidradenitis suppurativa: a cross-sectional study. $\mathrm{Br} J$ Dermatol. 2014 Oct;171(4):819-24.
3 Heatherton TF, Kozlowski LT, Frecker RC, Fagerström KO. The Fagerström Test for Nicotine Dependence: a revision of the Fagerström Tolerance Questionnaire. Br J Addict. 1991 Sep;86(9):1119-27.
4 Etter JF, Bergman MM, Humair JP, Perneger TV. Development and validation of a scale measuring self-efficacy of current and former smokers. Addiction. 2000 Jun;95(6):901-13.

5 Vink JM, Willemsen G, Beem AL, Boomsma DI. The Fagerström Test for Nicotine Dependence in a Dutch sample of daily smokers and ex-smokers. Addict Behav. 2005 Mar;30(3): 575-9. 